\title{
25. Scientists, Statisticians and the Prophets of Doom ${ }^{1}$
}

\author{
Ian Castles
}

In the Unnatural Nature of Science (1992), Lewis Wolpert, FRS, Professor of Biology at University College, London, concluded that 'Science is one of humankind's greatest and most beautiful achievements and for its continuation, free and critical discussion, with no political interference, is as essential today as it was in Ionia'. ${ }^{2}$

In principle, the international science community accepts the vital importance of such 'free and critical discussion', and asserts the need for these values of science to be applied to the world's problems. The most recent such proclamation came from 63 academies of science after a meeting in Tokyo in May 2000:

Science is, in a very fundamental sense, the process of seeking the truth. The values of the scientific enterprise - openness, community, quality and respect for evidence - are of great importance and application to the search for sustainability. The scientific community must be involved in the broad interactive process of establishing societal priorities...and in fostering the public understanding and the political will to ensure that progress moves in directions that correspond to those priorities. ${ }^{3}$

Regrettably, however, there are many in the science community who are more strongly committed to implementing their priorities than to the values of the scientific enterprise. This has recently been demonstrated in their enraged reaction to The Skeptical Environmentalist by Bjorn Lomborg, ${ }^{4}$ a book that takes issue with the claim that the pursuit of economic progress inevitably leads to an ever-deteriorating environment. Lewis Wolpert, for one, has found it convincing:

At last a book that gives the environment the scientific analysis it deserves, and provides understanding of the problems, the risks and the solutions. Essential Reading. ${ }^{5}$

\footnotetext{
1 This article was first published as 'The Skeptical Environmentalist and his Critics' in Dialogue (3/2001), the journal of the Academy of the Social Sciences in Australia.

2 Wolpert, Lewis (1992). The Unnatural Nature of Science: 128

3 InterAcademy Panel (2000). Transition to Sustainability in the 21st Century: the Contribution of Science and Technology [A statement of the World's Scientific Academies (May)] (http://interacademics.net/intracad/ tokyo2000.nsf).

4 Lomborg, Bjorn (2001). 'The Skeptical Environmentalist: Measuring the Real State of the World', Cambridge University Press, Cambridge.

5 Ibid: back cover.
} 
But many other scientists are unhappy at the attention that is being given to an alternative view, as James Woodford revealed in his review of the book for the Sydney Morning Herald:

For 350 pages, backed up by nearly 3000 footnotes, the Danish statistician critically examines the slogans and arguments that have galvanised much of the developed world into environmental action. It is a book that the green movement would love to see pulped; several people I have spoken to about the text have asked me not to give Lomborg any more publicity. $^{6}$

Three of Lomborg's critics confronted him on the Earthbeat program on ABC Radio on 13 October. Alexandra de Blas introduced the segment with the comment that the new book 'has environmentalists and scientists from around the world fuming ${ }^{17}$ - and she introduced Tom Burke, environmental adviser to Rio Tinto and BHP, as the author of what she called a 'damning paper' on the book.

This was the pamphlet Ten Pinches of Salt, ${ }^{8}$ which was released by the UK Green Alliance on the same day as Lomborg's book was published by Cambridge University Press. At the launch, Burke labelled The Skeptical Environmentalist 'a dishonest and discreditable smear on the many millions of professionals and volunteers working to improve the environment', and claimed that the positions that Lomborg had attacked 'a caricature of his own invention which bear no resemblance to the arguments currently deployed by environmentalists'. ${ }^{9}$

On Earthbeat, Alexandra de Blas asked Burke to outline his main concerns with the publication. He began his response by challenging Lomborg's credentials. He (Burke) had 'actually talked to Greenpeace, and they are very clear that they have no record of Bjorn Lomborg... as an activist member'. When Lomborg responded that he had 'never been out in a rubber boat' but was 'a suburban kind of Greenpeace member', Burke replied:

That doesn't make you an environmentalist, Bjorn. I mean that would make me a statistician because I've done some calculations. ${ }^{10}$

Tom Burke is certainly not a statistician, and it is not possible to identify his area of expertise either from his pamphlet or his comments on Earthbeat. In the former, he acknowledged that the Club of Rome had been wrong to argue

6 Woodford, James (2001). 'A load of hot air' in the Sydney Morning Herald, 29-30 September: Spectrum: 4-5.

7 ABC (2001). 'Skeptical Environmentalist Debates Critics', Earthbeat, Radio National Home, http://www.

abc.net.au/rn/science/earth/stories/s394496.htm.

8 Burke, Tom (2001). Ten Pinches of Salt: A Reply to Bjorn Lomborg, http:/www.green-alliance.org.uk.

9 Green Alliance (2001). 'What's New', 29 August, http://www.green-alliance.org.uk/WhatsNew.htm.

10 ABC (2001). Op cit: 2-3. 
that 'natural resources are running out', and that 'Paul Erlich [sic] did make and lose, his famous wager with Julian Simon'. But he asserted that, as of now, 'Environmentalists do not believe that natural resources are running out', and questioned 'what is gained in 2001 by resurrecting a long dead argument only to kill it all over again?'. ${ }^{11}$

Far from being 'long dead', the argument is alive and well in the scientific community: it is just that it is now presented in a somewhat more sophisticated guise than the simplistic models, made notorious by the Club of Rome and the writings and lectures of Ehrlich (Professor of Biological Sciences at Stanford). For example, the statement in May 2000 by 63 academies of science declared that human consumption reduces 'the future availability of materials and energy', and that 'if current trends in ...consumption of energy and materials...persist, many human needs will not be met and the numbers of hungry and poor will increase'. ${ }^{12}$

Perhaps the academies do not realise it, but this assertion effectively implies that 'natural resources are running out'. If they are not, why would growth in the usage of such resources work against the satisfaction of human needs, and lead to increases in the numbers of hungry and poor?

Burke recognises that 'Professor Erlich [sic] did predict in his book The Population $B o m b$, published 23 years ago, that 'In the course of the 1970s the world will experience starvation of tragic proportions - hundreds of millions of people will stave [sic] to death'. And he even goes on to argue that Ehrlich

was, as we all too often witnessed from the comfort of our living rooms, right...but I cannot recall, and Professor Lomborg does not cite, another occasion on which he made this prediction. ${ }^{13}$

This is wrong on a number of counts. First, Lomborg does cite another occasion - an article in The New Scientist in which Ehrlich urged the US to announce 'that we will not longer send emergency aid to India where sober analysis shows a hopeless imbalance between food and population'. ${ }^{14}$ Second, there were many more such occasions: in 1969, a New York Times correspondent reported that the Stanford biologist 'turns out a steady stream of popular articles and books warning of unimaginable famine, nuclear destruction and plague if something isn't done quickly about rising population'. ${ }^{15}$ Thirdly, no one denies that there

11 Burke, Tom (2001). Op cit: 6.

12 InterAcademy Panel (2000). Op cit.

13 Burke, Tom (2001). Op cit: 6 - 7.

14 Lomborg, Bjorn (2001). Op cit: 350.

15 New York Times (1969). 'Foe of Pollution Sees Lack of Time', August 10: 53 (emphasis added). 
are and always have been starving people in the world, including in the 1970s: images on television screens can only testify to that tragic fact, not to the existence of 'unimaginable famine'.

But, finally, and most importantly, Burke is apparently unaware that the spectre of the imminent deaths of hundreds of millions raised by Paul Ehrlich in his 1968 book was not a 'prediction': it was the most optimistic of three 'scenarios' that he offered as a description of the 'kinds of disasters that will occur as mankind slips into the famine decades' - and he challenged his readers to create a more optimistic one.

Paul Ehrlich was explicit that his scenario presuming 'the death by starvation of perhaps as many as half a billion people' was a 'cheerful' one with 'considerably more appeal than the others'. His fear was that it involved 'a maturity of outlook and behaviour in the United States that seems unlikely to develop in the near future'. For example, it would require the suspension of food shipments to 'India, Egypt and some other countries which [the US] considers beyond hope'; the imposition of 'a moderate food rationing program' in the US itself; and the development of a plan to contain the world's population to two billion in 2025 and 1.5 billion in 2100 .

The scenarios that Ehrlich considered more likely envisaged either an early global war induced by pressures on food supplies, with more than 100 million Americans dying from the fallout from Chinese thermonuclear devices 'transported in submarines [and] detonated in the sea off our West Coast'; or famines, plagues and anarchy leading to 'a general thermonuclear war' in the 1980s, making the entire globe uninhabitable by humans. The most intelligent creatures ultimately surviving this catastrophe would be cockroaches. ${ }^{16}$

Understandably, Tom Burke and the millions he believes to have been smeared by Lomborg's analysis would prefer these false prophecies of doom to be forgotten. They would like to anathematise Matt Ridley, author of Genome, for his advice to every environmentalist to read Lomborg's book 'so that the appalling errors of fact the environmental movement has made in the past are not repeated' ${ }^{17}$

Under the sarcastic heading 'Simon says', Burke alleges that Lomborg dismisses the issue of waste by leaning heavily 'on data from his mentor, Julian Simon', and claims that The Skeptical Environmentalist 'fails to mention toxic or hazardous wastes'. ${ }^{18}$ To a lay person, this does not appear to be so. For example, Lomborg cites US statistics showing decreases between 1986 and 1995 in the concentrations of pollutants in mussels of ' 28 percent for cadmium, 36 percent

16 Ehrlich, Paul R (1968). The Population Bomb, New York: 72-80.

17 Lomborg, Bjorn (2001). Op cit: back cover.

18 Burke, Tom (2001). Op cit: 8. 
DDT, 48 percent polychlorinated biphenyl (PCB), 56 percent dieldrin, 62 percent polycyclic aromatic hydrocarbons (PAH) and 86 percent butyl tin'; and Danish statistics showing 'declines of DDT and PCB in saltwater fish of more than 90 percent since 1973'. And he quotes from the latest US State of the Coastal Environment report the statement that 'most pollutant concentrations are decreasing and none is increasing'. ${ }^{19}$

Burke goes on to give the following summary of Lomborg's account of the relationship between air pollution and income levels in developing countries:

Air pollution in the rest of the world, where two-thirds of humanity lives, need not be considered, in Professor Lomborg's view, because this will cease automatically as they get richer. This confuses cause and correlation, not a mistake you would expect from a statistician. ${ }^{20}$

But Lomborg does consider air pollution in developing countries and does not claim that it will cease automatically as they get richer. Indeed he recognises that the tendency is for air pollution to continue to rise in developing countries until incomes reach medium levels. Beyond those medium income levels, however, he argues that the tendency is for air pollution to fall (not 'automatically', but as a result of public preferences and political decisions) to 'the level [those countries] had before they started developing'.

Lomborg assembles the evidence for these propositions in the form of charts showing the connection between GDP per capita and particle and $\mathrm{SO}_{2}$ pollution for 48 cities in 31 countries, for each of the years 1972 and 1986. The analysis includes cities in the developed world and in China, India, Thailand, the Philippines, Korea, Brazil, Chile, Colombia and Venezuela. It shows that, between these two years, both types of pollution fell for all nations at all levels of wealth. Lomborg concludes that 'developing countries can not only achieve both economic growth and a better environment, but over time will get even better environment for a given amount of wealth':

this is because developing countries can buy progressively cheaper, cleaner technology from the West. The key factor here is that technology makes it possible to achieve growth as well as a better environment. ${ }^{21}$

Many scientists have become so accustomed to thinking of growth and the environment as opposites that they are unable to accept the clear message of the empirical evidence on this fundamental point. Thus Ian Lowe, Emeritus

19 Lomborg, Bjorn (2001). Op cit: 195.

20 Burke, Tom (2001). Op cit: 9 (emphases added).

21 Lomborg, Bjorn (2001). Op cit: 176-7. 
Professor of Science, Technology and Society at Griffith University - another critic of The Skeptical Environmentalist on the ABC Earthbeat segment - claimed that

...to say the problems [of the environment] will be solved by greater wealth and private property rights is economic dogma...not science. There's no convincing evidence that greater wealth necessarily leads to environmental improvement. Even Bjorn's figures show that in some cases greater wealth makes the environment better, in others it clearly makes it worse. It all depends on the starting point and what options people have. ${ }^{22}$

Again, this is a distortion of Lomborg's argument. It is the denial of the proposition that problems of the environment can be solved by greater wealth that represents dogma, not science. Of course it is possible, with ill-considered policies, for the average wealth of medium income countries to increase and for the environment to deteriorate: this was demonstrated by the experience of the Warsaw Pact countries in the 1950s and 1960s. But Lomborg provides strong evidence that in mixed market economies with democratic institutions, the growth of income above a medium level (a level that much of the developing world has either achieved or can be expected to achieve in the not-so-distant future) will lead to environmental improvement and not the reverse.

A major reason for this, as Lomborg points out, is that advancing technology facilitates both growth in average incomes and improvements in the environment. Ian Lowe cannot see this because his conceptual schema puts technology and 'wealth' into separate boxes, and assigns the interest in 'wealth' to a discipline whose practitioners are supposed to have no understanding of technology:

One particular problem in Australia is that much of the advice reaching government comes from economists who have no understanding of technology...(K)ey areas of the Commonwealth Public Service are thickly infested with economists, carrying with them the bizarrely simplistic view that technological change is predominantly an economic activity. There is every reason to argue that technological literacy should be more widespread; in a modern society it could almost be argued to be a prerequisite for positions of responsibility to understand the general principles of technology. ${ }^{23}$

On the Earthbeat program on 13 October, the third of the invited contributors, Stephen Schneider, responded as follows to Alexandra de Blas' inquiry as to why he was so 'red hot under the collar' about Lomborg's book:

$22 \operatorname{ABC}(2001)$. Op cit: 8 (emphasis added).

23 Lowe, Ian (1988), 'The Mushroom Treatment', Australian Society, 12-13 November, (emphasis added). 
Well, for those of us who in my case have spent about three decades working with thousands of scientists and policy analysts and others, trying to figure out something about...the future we face...we end up with a maddening degree of uncertainty...We fight amongst ourselves... and have virtually no agreement and now all of a sudden I see in The Skeptical Environmentalist the sub-title 'Measuring the Real State of the World', and the person who's a non-contributor to the debate has selected largely out of context the happier news. ${ }^{24}$

Schneider, who is Professor of Environmental Biology and Global Change at Stanford, was 'angry' at CUP for publishing Lomborg's book. Asked by de Blas whether this was 'just a case of the old boys' club getting their noses out of joint because there's a new voice with a very different message', Schneider responded:

It was published from the social and political science part of the shop, yet this book requires a tremendous amount of natural science, physical and biological sciences, upon which a lot of these conclusions about social science are based. And what Cambridge should have done... and I've held them...quite derelict for this, [was] have reviewers across all three of the groups...so they could have found out whether the grounding in other disciplines was a balanced treatment...and I think had they done that, they would have made a very different conclusion about publishing the book. ${ }^{25}$

It is not clear that this is so: Lewis Wolpert, for one, would presumably have advised Cambridge to publish the book if his opinion had been sought. And many of the 'thousands of scientists and policy analysts and others' to whom Schneider refers might not agree that an intelligent and persuasive voice should be denied a hearing for the reasons he gives.

It is perhaps fortunate for Stephen Schneider that Bjorn Lomborg did not review Schneider's contributions to the debate on global climate change and associated issues during the past 30 years. Some of these are worth recording here - not for the purpose of casting doubt on Schneider's distinction as a scientist, but in order to show that the stones he throws at Lomborg come from the occupant of a glass house. Here is Schneider's assessment of the prospective direction of global climate change from a book published in 1976:

I have cited many examples of recent climatic variability and repeated the warnings of several well-known climatologists that a cooling trend

24 ABC (2001). Op cit: 3.

25 Ibid: 8. 
has set in - perhaps one akin to the Little Ice Age - and that climatic variability, which is the bane of reliable food production, can be expected to increase along with the cooling. ${ }^{26}$

In 1989, by which time Schneider was calling for immediate action to check the prospect of global warming, he gave his view of the way scientists should contribute to the debate:

...like most people [we scientists] would like to see the world a better place, which in this context translates into our working to reduce the risk of potentially disastrous climatic change. To do this we need to get some broad-based support, to capture the public's imagination. That, of course, entails getting loads of media coverage. So we have to offer up scary scenarios, make simplified dramatic statements, and make little mention of any doubts we might have. This 'double ethical bind' we find ourselves in cannot be solved by any formula. Each of us has to decide what the right balance is between being effective and being honest. I hope that means being both. ${ }^{27}$

In a recent lecture in India, Deepak Lal, Professor of International Development Studies at UCLA, recalled how he became involved in debates on the environment when he was preparing the 1990 Wincott Lecture:

Having read the scientific literature I was appalled at how the scientists - like Stephen Schneider - openly admitted they were creating alarm for a phenomenon they themselves recognised as highly speculative. My lecture not surprisingly ended up as an attack on this scientific attempt to bamboozle the public. ${ }^{28}$

While Schneider sees himself as justified in making 'little mention' of his doubts, he condemned Lomborg on the Earthbeat program for having 'a confidence that's not based on any significant analysis by him, or any properly balanced citation from the literature'. ${ }^{29}$ As the preceding discussion shows, Lomborg's analysis cannot be so lightly dismissed. As a professor of statistics in a school of political science, he is better equipped to assess the relevant evidence, and to understand the processes by which societal priorities are determined, than many of his critics.

At the conclusion of the Earthbeat segment on ABC Radio on 13 October, Lomborg summed up his position as follows:

26 Schneider, Stephen (1976). The Genesis Strategy, New York: 90.

27 Quoted by Jonathan Schell (1989). ‘Our Fragile Earth', Discover, October: 47.

28 Lal, Deepak (2000). 'The New Cultural Imperialism: the Greens and Economic Development', The Inaugural Julian Simon Memorial Lecture, Liberty Institute, New Delhi, 9 December: 3.

29 ABC (2001). Op cit: 3. 
Yes, I'm a political scientist, economist, statistician. Yes, we do actually look at things in a different way. I asked the question which is fundamental to democracy and to our prioritisation process: 'So overall, how are things going?' A lot of these people would like to sit on the debate and say 'We have the right answer'. Well, no, they have the right understanding in many of these models, but the basic question of what should we do, how things are basically going, needs also to come out there, and that I think has not been coming out from science. But certainly we need to get that overview of the world and that is what I've tried to provide. ${ }^{30}$

Lomborg has made an outstanding contribution to the discussion of some of the most vital issues of our time. If parts of his analysis are unsound on scientific grounds, it should not be beyond the capacity of scientists to demonstrate this in free, critical and civil discussion. Those who have chosen instead to distort or suppress his message, or to engage in ill-tempered abuse, are doing a disservice to themselves, their disciplines and scientific enterprise. 